\title{
Factors affecting the healing rate of duodenal and pyloric ulcers with low-dose antacid treatment
}

\author{
S MASSARRAT* AND A EISENMANN \\ From the Medical Polyclinic, Philipps-University, Marburg, West Germany
}

SUMMARY In 80 patients with duodenal ulcer, the effects of various factors-symptoms, endoscopic findings, and peak acid output (PAO) - on the healing rate were studied during eight weeks of outpatient therapy with low-dose antacid (neutralising capacity less than $50 \mathrm{mmol} \mathrm{HCl} / \mathrm{d}$ ). Fifty-six per cent of the ulcers healed. The following unfavourable factors were found to cause a significant delay in ulcer healing: a long duration of pain in the last ulcer relapse and the present period of ulcer pain, smoking, stenosis of the duodenal bulb, and a high PAO. Multiple regression analysis showed that three factors (duration of the present ulcer pain, smoking, and stenosis of the duodenum) had a significant influence on healing rate. According to the results obtained with this method, the patients with no or only one unfavourable factor $(n=35)$ had the best healing rate: $80 \%$, compared with patients who had two $(n=31)$ or three $(n=14)$ unfavourable factors. The healing rate of the latter two groups was $41 \%$ and $28 \%$, respectively $(\mathrm{P}<0.001)$. A prognostic score based on these three factors represents the severity of duodenal-ulcer disease with regard to the healing process under placebo-like doses of antacid.

\begin{abstract}
While the number of studies on the effect of various therapeutic regimens on the healing rate of duodenal ulcer has increased in recent years, no generally accepted criteria have yet been set up for assessing the severity of the disease and for comparing the subjects investigated in various centres. The aim of the present investigation was to evaluate the effect of the various characteristics of ulcer patientssymptoms and complaints, endoscopic findings, and the extent to which gastric-acid secretion influences the healing of duodenal ulcer under low-dose antacid treatment for a period of eight weeks in outpatients.
\end{abstract}

\section{Methods}

From February 1975 to the end of 1976, diagnosis of peptic ulcer was made in 200 German patients, most of whom had been referred to our clinic by general practitioners for diagnosis. On the day of endoscopic examination all patients were given a standard questionnaire about their symptoms and history. The duration of ulcer disease was dated from the inception of ulcer-like symptoms. All

Address for correspondence: Professor Dr S Massarrat, Medizinische Universitäts-Poliklinik Emil-Mannkopf-Strasse, 3550 Marburg, West Germany.

Received for publication 2 December 1980 patients who regularly smoked more than five cigarettes per day were considered as smokers, and those who consumed at least $50 \mathrm{~g}$ of alcohol per day were regarded as drinkers. All ulcers located in the pyloric canal or prepyloric region with a margin in the canal area were considered to be duodenal ulcer. Ulcer size was assessed by measuring the greatest diameter with the tip of open forceps. In cases of multiple ulcers, the diameter of the largest ulcer was measured. Those ulcers whose base appeared to be almost on a level with the surrounding mucosa were called flat, and those with a clearly depressed base more than 2 or $3 \mathrm{~mm}$ from the margin were called deep. All swollen and erythematous mucosa, with or without a white fibrin layer close to or remote from the ulcer site, was considered as a sign of inflammation. Each circular narrowing of the duodenal bulb by swollen mucosa or wall deformity was considered as stenosis, regardless of its extent. If inflation of the stomach caused sufficient protrusion, large corpus folds were assumed to be present. The severity of the symptoms, and the extent of pain and appetite, were rated according to the patient's own estimate. There was no quantification of other symptoms or endoscopic findings. All endoscopic findings were recorded after each endoscopy. The endoscopist was not aware of the patient's symptoms when he performed the endoscopies. Gastric-secre- 
tion analysis was made under pentagastrin stimulation $(6 \mu \mathrm{g} / \mathrm{kg})$. The peak acid output (PAO) was calculated.

During a period of eight weeks, each of these outpatients was given antacids three to five times daily, depending upon the occurrence of pain. These antacids contained $0.5 \mathrm{~g}$ magnesium-aluminium silicon hydrate (Gelusil-Lac), with a neutralising capacity of $8 \mathrm{mmol} \mathrm{HCl}$, or $2 \mathrm{~g}$ aluminium phosphate (Phosphalugel), with a neutralising capacity of $3.5 \mathrm{mmol} \mathrm{HCl}$. All total daily doses had a neutralising capacity of less than $50 \mathrm{mmol} \mathrm{HCl}$. The patients were advised to take several small meals per day, and to abstain from smoking. Aspirin was replaced by paracetamol when necessary. Patients with severe pain were advised to stop working.

During the control examination, these patients were questioned about their working habits, smoking, and any changes in medication during the interval. An ulcer was considered to be healed only if control endoscopy showed complete epithelialisation or a scar. All results were evaluated with the chi square test, Student's $t$ test, or the Mann-Whitney test, and multiple stepwise regression analysis. ${ }^{1}$ All factors which were statistically unfavourable for duodenal ulcer healing were weighted equally, and used for

Table 1 Characteristics of patients with healed $(n=45)$ and non-healed $(n=35)$ duodenal ulcer

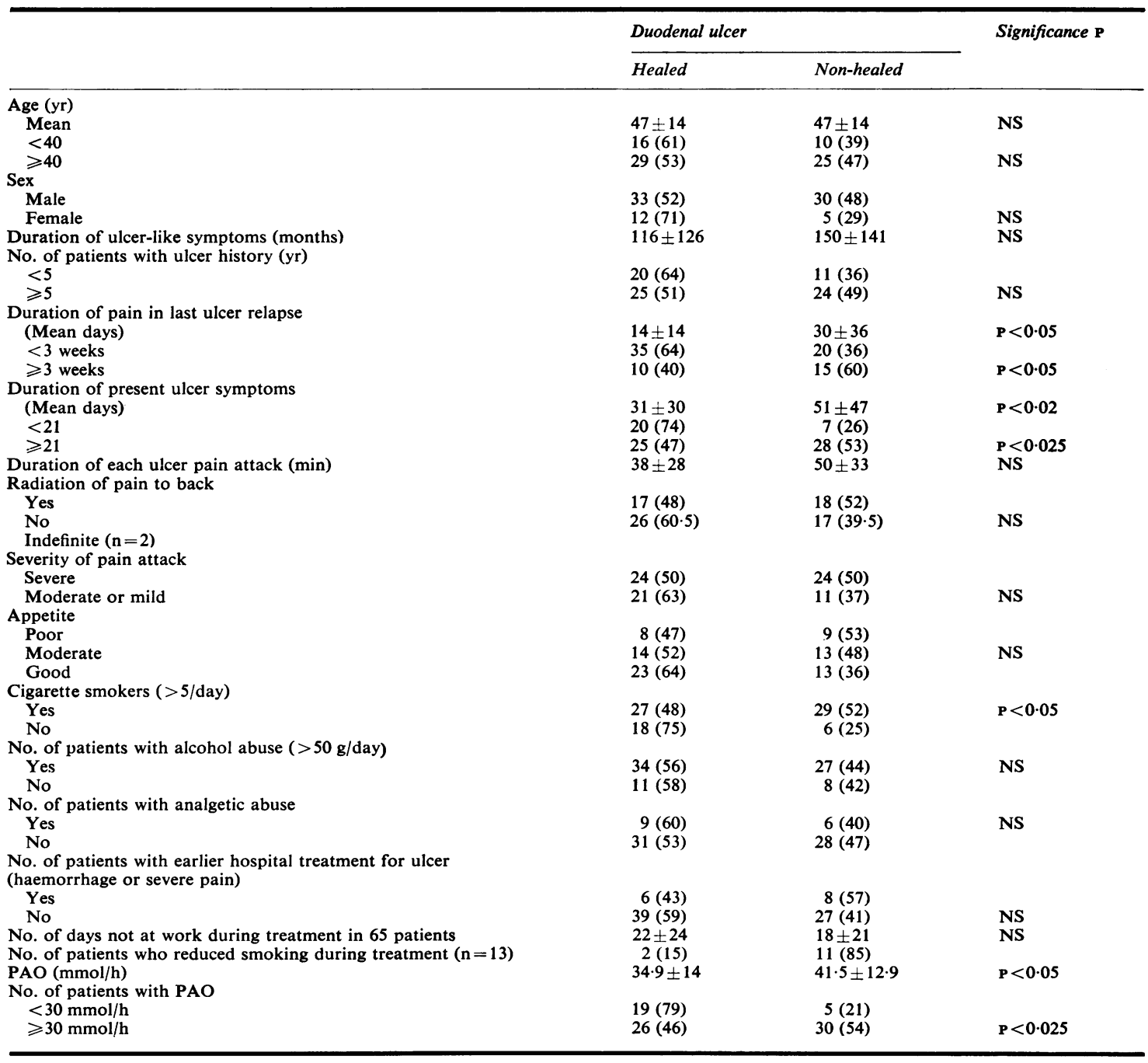

- Percentage in parentheses, mean $\pm 1 \mathrm{SD}$. 
calculating a prognostic score. The healing rate was then estimated on the basis of this score.

Results

Of 200 German patients with an initial diagnosis of peptic ulcer (gastric or duodenal), 39 patients were excluded from the follow-up study for various reasons (incompleteness of available data in 24 cases, gastric surgery in one, therapy other than antacids in eight, death unrelated to ulcer disease in two, surgery for ulcer complications during the interval in four cases). Thirty-eight patients had gastric ulcer (not considered in this study). There remained 123 patients with duodenal ulcer; of these, 26 patients refused to participate in the control examination and 17 patients refused to undergo gastric-secretion analysis. Complete data were thus available on 80 patients with duodenal ulcer. All clinical and endoscopic data on 43 patients with duodenal ulcer not included in the study were comparable with those of 80 patients in this study, except for the intensity of pain (which was significantly less in the excluded patients, $P<0.05$ ) and for the number of ulcers (which were less multiple in the excluded group, $\mathrm{P}<0.025)$. The same endoscopist (SM) performed $88 \%$ of all the endoscopic examinations (first and second control). The remaining examinations were carried out by two experienced endoscopists, and in at least one of the two endoscopic examinations the first endoscopist (SM) was present.

Table 1 shows the various characteristics of the patients with healed or unhealed duodenal ulcer. The ulcer had healed in 45 of the 80 patients $(56 \%)$.

Among the various characteristics of ulcer disease, the duration of the pain in both the last ulcer relapse and the present attack was of significant importance for the healing rate. In addition, smokers had a significantly worse healing rate than non-smokers. The duration of ulcer disease, extent of appetite, severity of pain, radiation of pain to the back, abuse of analgesics, and previous hospital treatment had some effect on the healing rate, but the values did not reach the threshold of significance.

Among the endoscopic data (Table 2), stenosis of the duodenal bulb had a significant delaying effect on healing. Irregular, deep, or large ulcers healed worse than those without these characteristics. Inflammation close to or remote from the ulcer, and large corpus folds, seemed to have a delaying effect on healing, but the differences were not significant. All patients with unhealed ulcers had a significantly higher PAO than those whose ulcers had healed. Ulcers in the patients with a PAO of less than 30 $\mathrm{mmol} \mathrm{HCl} / \mathrm{h}$ healed better than those in patients with a higher PAO. Multiple linear regression
Table 2 Characteristics of endoscopic findings in healed $(n=45)$ and non-healed $(n=35)$ duodenal-ulcer patients*

\begin{tabular}{|c|c|c|c|}
\hline & \multicolumn{2}{|c|}{ Duodenal ulcer } & \multirow[t]{2}{*}{ Significance $\mathbf{P}$} \\
\hline & Healed & Non-healed & \\
\hline \multicolumn{4}{|l|}{ Ulcer shape } \\
\hline Round or oval & $36(59)$ & $26(41)$ & \\
\hline Irregular & $6(40)$ & $9(60)$ & NS \\
\hline Indefinite $(n=3)$ & & & \\
\hline \multicolumn{4}{|l|}{ Ulcer size $(\mathrm{mm})$} \\
\hline$<8$ & $18(64)$ & $10(36)$ & \\
\hline$\geqslant 8$ & $27(52)$ & $25(48)$ & NS \\
\hline \multicolumn{4}{|l|}{ Ulcer depth } \\
\hline Flat & $24(60)$ & $16(40)$ & \\
\hline Deep & $21(52)$ & $19(48)$ & NS \\
\hline \multicolumn{4}{|l|}{ Number of ulcers } \\
\hline Single & $27(60)$ & $18(40)$ & \\
\hline Multiple & $18(51)$ & $17(49)$ & NS \\
\hline \multicolumn{4}{|c|}{ Inflammation near ulcer } \\
\hline Yes & $32(59)$ & $27(41)$ & \\
\hline No & $13(62)$ & $8(38)$ & NS \\
\hline \multicolumn{4}{|c|}{ Inflammation remote } \\
\hline \multicolumn{4}{|c|}{ from ulcer } \\
\hline Yes & $20(50)$ & $20(50)$ & \\
\hline No & $25(62)$ & $15(38)$ & NS \\
\hline \multicolumn{4}{|l|}{ Stenosis of bulb } \\
\hline Yes & $14(41)$ & $20(59)$ & \\
\hline No & $31(67)$ & $15(33)$ & $P<0.05$ \\
\hline \multicolumn{4}{|c|}{ Erosions in antral region } \\
\hline & $21(55)$ & $17(45)$ & \\
\hline No & $24(57)$ & $18(43)$ & NS \\
\hline \multicolumn{4}{|l|}{ Large fold in corpus } \\
\hline Yes & $16(47)$ & $18(53)$ & \\
\hline No & $29(63)$ & 17 (37) & NS \\
\hline
\end{tabular}

-Percentage in parentheses.

analysis (SPSS programme) was used to check the effect of the following 18 characteristics on the healing rate: age; duration of ulcer history; duration of pain in the last ulcer relapse and the present period of ulcer pain; severity of pain; poor appetite; vomiting; heavy smoking; alcohol consumption; previous hospital treatment; ulcer size; ulcer depth; number of ulcers; inflammation close to and remote from the ulcer; large corpus folds; stenosis of the duodenal bulb, and PAO. The analysis showed that the ulcer healing rate is significantly affected by the following three independent factors: long duration of present ulcer pain $(P<0.05)$, stenosis of the bulb $(P<0 \cdot 001)$, and smoking $(P<0.01)$. PAO was not considered as being important in this analysis, largely because of the dependence of PAO on smoking. The correlation coefficient between these two factors was $0.24(\mathrm{P}<0.02)$; that between smok-

Table 3 Healing rate and number of unfavourable factors

\begin{tabular}{|c|c|c|c|c|}
\hline \multirow[t]{2}{*}{ Patients with } & \multicolumn{4}{|c|}{ Score } \\
\hline & 0 & 1 & 2 & 3 \\
\hline $\begin{array}{l}\text { Healed ulcer } \\
\text { Non-healed ulcer } \\
\text { Healing rate }(\%)\end{array}$ & $\underbrace{4}$ & $\begin{array}{r}24 \\
7 \\
-\end{array}$ & $\begin{array}{l}13 \\
18 \\
42\end{array}$ & $\begin{array}{r}4 \\
10 \\
28\end{array}$ \\
\hline
\end{tabular}

$\mathrm{P}<0.001$. 
ing and stenosis of the bulb was 0.04 , and that between smoking and duration of the present ulcerpain period was 0.05 . PAO was additionally correlated with duration of ulcer-like symptoms $(r=$ $0.23, \mathrm{P}<0.02)$, with sex $(r=0.4, \mathrm{P}<0.001)$, and with duration of each attack of ulcer pain $(r=0.22$, $P<0.025)$. In the 56 patients who smoked, PAO amounted to $40 \mathrm{mmol} \mathrm{HCl} / \mathrm{h}( \pm 12 \cdot 9,1 \mathrm{SD})$, and to $32.7( \pm 15.1) \mathrm{mmol} \mathrm{HCl} / \mathrm{h}(\mathrm{P}<0.05)$ in the 24 nonsmokers.

According to the results obtained by multiple stepwise regression analysis, patients with varying numbers of a total of three unfavourable factors (duration of present ulcer pain for more than three weeks, smoking, duodenal stenosis) were classified into four groups (Table 3). As the prognostic score increases from 0 to 3 in these four groups, the healing rate decreases from $80 \%$ (score of 0 to 1 ) to $28 \%$ (score of 3).

\section{Discussion}

In multicentre clinical trials with cimetidine, the healing rate of duodenal ulcer in outpatients under placebo as assessed by endoscopic examination during a fixed period of four to six weeks has been found to range widely in various countries. ${ }^{2}$ Many of the studies do not mention the various characteristics of the patients; some of them ${ }^{34}$ present no data on the patients, or report only on age and sex. ${ }^{5}$ The duration of ulcer disease is mentioned in most of the studies. ${ }^{6-15} \mathrm{~A}$ few studies give the duration of ulcer relapse before the study, ${ }^{91112}$ the patients smoking habits, ${ }^{71115}$ or endoscopic data such as ulcer size, ${ }^{61314}$ duodenitis, ${ }^{10}$ erosions,${ }^{12}$ or the number of ulcers. ${ }^{7}$

In other clinical trials with pirenzepine, an anticholinergic agent, attention was paid to age, sex, length of ulcer history, history of ulcer relapse, smoking habits, and the number and size of the ulcers as verified by endoscopy. ${ }^{16}$ These various profiles of the clinical data given in the multicentre studies clearly show that the differences in the views expressed are attributable to the lack of studies on the natural history of the healing process, and likewise indicate the importance of the various factors which can delay the healing of duodenal ulcer.

In these and other studies comparing placebo with other medication, the influence of the duration of ulcer disease on healing under placebo was controversial. ${ }^{617} \mathrm{Age}^{818}$ and the size of the ulcer were found to be without any effect on complete healing. ${ }^{6} 18$ In contrast, Scheuer et al..$^{19}$ showed that large ulcers require more time for complete healing, as has also been demonstrated for gastric ulcer. ${ }^{20}{ }^{21}$ The effect of smoking and its delaying influence on duodenal- ulcer healing was clearly shown by Peterson et al. ${ }^{18}$ and has been confirmed in another clinical trial. ${ }^{17}$

As the dose of antacid administered to our patients was very low and probably simply acted as a placebo ${ }^{22}$ amounting to less than $1 / 16$ of one effective dose, ${ }^{18}$ the healing rate in our patients probably corresponds to the rate of duodenal-ulcer healing under placebo. Our results indicate that, among the clinical data, the duration of the last ulcer relapse and the present ulcer symptoms are good indications for the healing process, being better than other clinical data, especially the duration of ulcer disease: patients with a pain period of more than three weeks had significantly more unhealed ulcers than patients with a shorter period. However, the duration of the present period of ulcer pain could be dependent upon the patient's awareness and personal reason for seeking a medical examination. It may be assumed that some patients with a short period of pain, whose ulcer was diagnosed early, could still have a severe course of healing because of their awareness of, and immediate attention to, the disease. Our patients with unhealed ulcers seemed to have a longer history of ulcer disease than those with healed ulcers; however, many of them could not remember when the disease began, and could only make a rough guess. On the other hand, the duration of the disease could hardly reflect its severity, because of the irregular appearance of relapses at varying intervals. Smoking had a delaying effect on healing, but reduction of, or abstention from, smoking during the eight-week control period had no clear effect on the few patients in this group. It can be assumed that a long period of abstention is necessary to improve the healing process in cases of duodenal ulcer.

Among the endoscopic data, stenosis of the duodenal bulb had a significant delaying effect on ulcer healing, but ulcer size had no significant effect on healing after eight weeks. Thus, it can be suggested that there are small ulcers that heal slowly, and large ulcers that heal quickly. On the other hand, it is possible that a short interval between initial and control endoscopy is necessary in order to distinguish the better healing rate of small ulcers in comparison with larger ones. Furthermore, in some cases it is difficult to assess the size of an ulcer in the duodenal bulb, because of stenosis and the impossibility of obtaining a clear view of the entire ulcer surface.

The patients with higher gastric-acid secretion (PAO greater than $30 \mathrm{mmol} \mathrm{HCl} / \mathrm{h}$ ) had ulcers which healed more slowly than those in patients with lower values. However, multiple regression analysis of our data shows that gastric-acid secretion depends upon other factors, in this case, probably, smoking. Our smoking patients had significantly more gastric 
acid secretion than our non-smokers. Therefore the three factors: long duration of the present period of ulcer pain, smoking, and stenosis of the duodenal bulb, each represent a prognostic sign for the healing process of duodenal ulcer. The greater the number of these unfavourable factors in a patient, the slighter the possibility that the ulcer will heal. The very good healing rate of duodenal ulcer under placebo in Switzerland is considered to be due to a geographic factor. ${ }^{23}$ However, as long as no clinical data concerning the unfavourable factors in these patients are available, the effect of geography on the healing rate of duodenal ulcer must remain doubtful.

The aim of further studies should be to evaluate the reliability of these factors in affecting the healing process under definite and effective treatment-for example, large doses of antacids or $\mathbf{H}_{2}$-blocking agents over a short period of time-and, furthermore, to ascertain the extent of the influence of these unfavourable factors on the healing rate, and to calculate an index for the severity of the disease and the long-term course of duodenal ulcer, similar to the activity index for Crohn's disease presently used for multicentre studies. ${ }^{24}$

\section{Addendum}

The reliability of the effect of these three unfavourable factors (smoking, more than three weeks' duration of the current relapse, and stenosis of duodenal bulb) on the healing rate of duodenal ulcer has been confirmed so far in a prospective study of 27 patients, who underwent three weeks' outpatienttreatment with antacids (aluminium and magnesium hydroxide gel, $10 \mathrm{ml}$ seven times daily, corresponding to a total neutralising capacity of 180 mmol $\mathrm{HCl})$. The ulcer was completely healed in 15 patients (healing rate amounts to $55 \%$ ). Depending upon the number of these unfavourable factors present in the patients, the healing rate observed is set out in the Addendum Table. These results suggest the importance of these factors for the healing process under treatment with high doses of antacid. Additional details of this current study will be published later.

Addendum Table Healing rate and number of unfavourable factors

\begin{tabular}{lrrrr}
\hline & \multicolumn{2}{c}{ Score } & & \\
\cline { 2 - 4 } & 0 & 1 & 2 & 3 \\
\hline $\begin{array}{c}\text { Patients with } \\
\text { healed ulcer }\end{array}$ & 1 & 10 & 4 & 1 \\
$\begin{array}{c}\text { Patients with } \\
\text { unhealed ulcer }\end{array}$ & 0 & 3 & 6 & 4 \\
\begin{tabular}{c} 
Healing rate \% \\
\hline
\end{tabular} & - & 76 & 40 & 20 \\
\hline
\end{tabular}

We wish to thank Professor Dr P Ihm and Dr R Holle of the Institute for Medical Statistics and Documentation of the Philipps-University of Marburg for their helpful advice and for carrying out the statistical analysis.

\section{References}

${ }^{1}$ Nie NN, Hull CH, Jenkins JG, Steinbrenner K, Dent DH. Statistical Package for the Social Sciences. New York: McGraw-Hill, 1975.

${ }^{2}$ Winship DH. Cimetidine in the treatment of duodenal ulcer, review and commentary. Gastroenterology 1978; 74: 402-6.

${ }^{3}$ Blackwood WS, Maudgal DP, Pickard RG, Lawrence D, Northfield TC. Cimetidine in duodenal ulcer, controlled trial. Lancet 1976; 2: 174-6.

${ }^{4}$ Northfield TC, Blackwood WS. Short communication: controlled clinical trial of cimetidine for duodenal ulcer. In: Burland WL, Simkins MA, eds. Cimetidine: Proceedings of the Second International Symposium on Histamine $\mathrm{H}_{2}$-Receptor Antagonists. Amsterdam: Excerpta Medica, 1977; 272.

${ }^{5}$ Giger M, Gonvers JJ, Weber KB, Sonnenberg A, Birchler R, Mattle W, et al. Therapie des Ulcus duodeni mit Cimetidin, Pirenzepin und Placebo. Schweiz med Wschr 1979; 109: 617-8.

${ }^{6}$ Bank S, Barbezat GO, Novis BH, Ou Tim L, Odes HS, Helman $\mathrm{C}$, et al. Histamine $\mathrm{H}_{2}$-receptor antagonists in the treatment of duodenal ulcer. $S$ Afr Med $J$ 1976; 50: 1781-5.

'Bardhan KD, Saul DM, Balmforth GV, Maruyama T, Duthie HL, Fussey IV, et al. The effect of cimetidine on duodenal ulceration. An interim report of a multicentre double-blind trial. In: Burland WL, Simkins MA, eds. Cimetidine: Proceedings of the Second International Symposium on Histamine $\mathrm{H}_{2}$-Receptor Antagonists. Amsterdam: Excerpta Medica 1977; 260-71.

${ }^{8}$ Binder JH, Cocco A, Crossley RJ, Finkelstein W, Font $\mathrm{R}$, Friedman $\mathrm{G}$, et al. Cimetidine in the treatment of duodenal ulcer. A multicentre double-blind study. Gastroenterology 1978; 74: 380-7.

${ }^{9}$ Bodemar G, Walan A. Cimetidine in the treatment of active duodenal and prepyloric ulcers. Lancet 1976; 2: $161-4$.

${ }^{10}$ Gillespie G, Gray GR, Smith IS, Mackenzie I, Crean GP. Short term and maintenance cimetidine treatment in severe duodenal ulceration. In: Burland WL, Simkins MA, eds. Cimetidine: Proceedings of the Second International Symposium on Histamine $\mathrm{H}_{2}$-Receptor Antagonists. Amsterdam: Excerpta Medica 1977: 240-7.

${ }^{11}$ Hetzel DJ, Hansky J, Shearman DJC, Korman MG, Hecker R, Taggart GJ, et al. Cimetidine treatment of duodenal ulceration, short term trial and maintenance study. Gastroenterology 1978; 74: 389-92.

${ }^{12}$ Ippoliti AF, Sturdevant RAL, Isenberg JI, Binder M, Camacho $\mathrm{R}$. Cano $\mathrm{R}$, et al. Cimetidine versus intensive antacid therapy for duodenal ulcer. A multicenter trial. Gastroenterology 1978; 74: 393-5. 
' 'Lambert R, Bader J-P, Bernier JJ, Bertrand J, Betourne C, Gastard J, Laverdant CL, Ribet A, Sahel J, Toulet J. Traitement de l'ulcère gastrique. Gastroenterol Clin Biol 1977; 1 : 855-60.

${ }^{\text {} 4}$ Peter P, Kiene K, Gonvers JJ, Pelloni S, Weber K, Sonnenberg A, et al. Cimetidin in der Behandlung des Ulcus duodeni. Ergebnisse einer Doppelblindstudie bei ambulant behandelten Patienten. Dtsch Med Wschr 1978; 103: 1163-6.

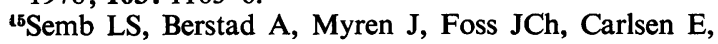
Kruse-Jensen A. A double-blind multicentre comparative study of cimetidine and placebo in short-term treatment of active duodenal ulceration. In: Burland WL, Simkins MA, eds. Cimetidine: Proceedings of the Second International Symposium on Histamine $\mathrm{H}_{2}-$ Receptor Antagonists. Amsterdam: Excerpta Medica, 1977: 248-53.

${ }^{16}$ Chierichetti SM, Gaetani M, Petrin G. Pharmacokinetic and clincal studies on pirenzepine, a new antiulcer drug. Scand J Gastroenterol 1979; 14: supplement 57.

${ }^{17}$ Lam SK, Lam KC, Lai CL, Yeung CK, Yam LYC,
Wong WS. Treatment of duodenal ulcer with antacid and sulpiride. Gastroenterology 1979; 76: 315-22.

${ }^{18}$ Peterson WL, Sturdevant RAL, Frankl HD, Richardson CT, Isenberg JI, Elashoff JD et al. Healing of duodenal ulcer with antacid regimes. $N$ Engl J Med 1977; 297: 341-5.

${ }^{19}$ Scheuer U, Witzel L, Halter F, Keller H-M, Huber R, Galeazzi R. Gastric and duodenal ulcer healing under placebo-treatment. Gastroenterology 1977; 72: 838-41.

${ }^{20}$ Nakajima T. Studies on factors affecting healing of gastric ulcers. Am J Gastroenterol 1976; 66: 150-4.

${ }^{21}$ Sun DCH, Stempien SJ. Site and size of the ulcer as determinants of outcome. Gastroenterology 1971; 61: 576-84.

${ }^{22}$ Hollander D, Harlam J. Antacids versus placebos in peptic ulcer therapy. JAMA 1973; 226: 1181-5.

${ }^{23}$ Blum AL, Siewert J-R, Walter F. Ulkustherapie mit Cimetidin. Dtsch Med Wschr 1978; 103: 135-9.

${ }^{24}$ Best WR, Becktel JM, Singleton JW, Kern F. Development of a Crohn's disease activity index. Gastroenterology 1976; 70: 439-44. 